\title{
Building Integrated Lightning Protection Technology and System Design
}

\author{
Xianjie Feng
}

Department of Architectural Engineering, Dongguan University of Technology, China

Email: fengxianjie@126.com

Keywords: Lightning Protection Zone; Based Lightning Protection and Grounding; Basic Grounding Network; Earthing Test; Flat Welding

\begin{abstract}
This project is a residential area, the project is composed of two towers and commercial podium, is a collection of commercial, office in a body's comprehensive construction, where two towers total height $46.8 \mathrm{~m}$. The project according to a class of building lightning protection grounding design, roof lightning protection zone, downlead, equalizing ring, earthing device and embedded parts are associated with the building structure, within the scope of general contracting project, the remaining part is responsible for the completion of the other units, and set aside the corresponding point to the metal railings, curtain wall, room and other parts of the need to ground.
\end{abstract}

\section{Lightning Protection and Grounding System Consists of the Following Components}

Lightning Protection Zone. In roof tower and podium have not greater than $5 \times 5 \mathrm{~m}$ and $6 \times 4 \mathrm{~m}$ lightning protection network. Glass curtain wall at the top of the metal frame must be connected with the lightning protection belt. All metal projections on the roof, ventilation pipe, fencing, sink lightning protection belt connected with the roof[1]. Electrical lines are through the roof and its steel distribution box, electrical equipment attached to the housing and connected to the nearby lightning protection devices. Roof installation equipment distribution box power supply side surge protector.

Downlead. This podium and the third phase of engineering use column diagonal within two root diameter greater than or equal to 16 main reinforcement welding as downlead jumper, peripheral using steel column as a second phase of tower lightning protection downlead, diagonal two core concrete used in the column diameter greater than or equal to $16 \mathrm{~mm}$ main reinforcement as lightning protection downlead. All down lead spacing is not more than $12 \mathrm{~m}$ and down lead based grounding network and roof lightning protection devices must follow pathways.

Equalizing Ring. Tower set equalizing ring for each layer, layer to the outer ring beam and steel column connection ring formation, and lead line connection, the formation of grading ring. Equalizing ring and each layer potential connection nets are welded together, on the podium roof and above the layer, the downlead lateral leads to 40x4 galvanized flat steel, glass curtain wall and metal frame connected, from equalizing ring place leads embedded parts and peripheral metal doors and windows, railings and other metal components connected, in case of flanking the thunder and lightning shielding effect.

Roof Pre-discharge Device. The lightning protection device is installed according to the Lightning Protection Office of Chongqing city and the final instruction of the first party. Specific installation location requires a combination of architectural appearance determined.

Equipotential Connection. Each equipment room, each machine tube well by the ground net, through lead bonding plate, by grounding network will indoor metal pipe, equipment, metal shell and PE main equip potential connection. Each floor slab is provided with an equal potential connection net, which is connected with the metal pipe, the metal casing and the PE main line of the pipeline well, the electric shaft and the elevator shaft. The weak current host room, swimming pool, shower, toilet and other set of local and other potential connection.

Based Lightning Protection and Grounding. Electrical grounding, security grounding, lightning protection, fire alarm systems and other weak ground share the grounding device. Using underground floor and moderators reinforcement and foundation reinforcement for grounding 
device[2]. In the part of the ground down lead deaden test terminal. Joint earthing system resistance must not be greater than $1 \mathrm{ohm}$, where required leads to ground connection plate.

Anti-lightning Invasion. Each weak current equipment room with wire pillar distance and shielding, earthing and equip connection, installation of overvoltage protection in the system. Each low-voltage incoming cabinet and equipment distribution box, weak-current equipment room power box power box, other devices need to install surge protectors.

Reserved Ground Terminal. In the roof is equipped with window cleaning machine, advertising lighting, billboards, etc., according to the design and approval of the design and approval of the owner of the instructions to carry out the reservation.

\section{The Overall Planning Engineering of Lightning Protection}

Lightning protection construction with steel structure construction process, in accordance with the civil construction segment, mine engineering can be divided into the following stages, etc.

The Construction Phase. The construction time of the bottom plate is carried out according to the construction progress of the pile foundation, the Foundation II project is divided into several areas, such as in Figure 1.

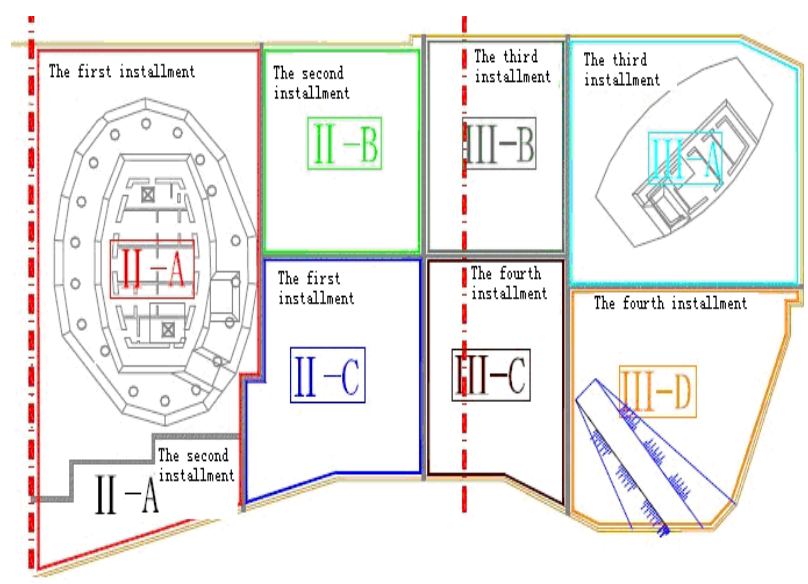

Fig. 1. Construction zoning diagram

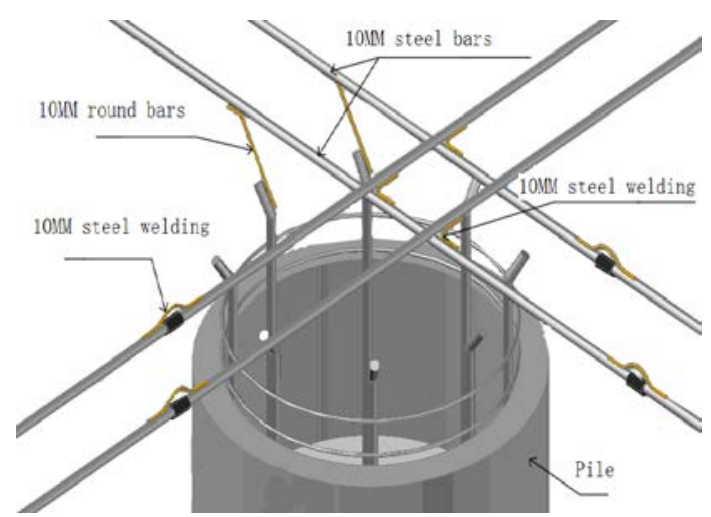

Fig. 2. Reinforcement connection diagram

The regional construction order for the II-A, II-A-1, and II-B, and III-A and III-B, and II-C, and III-C, and III-D. In the II-A, II-A-1 area of the mine construction process, phase grounding bar reserved basis must be connected, ensure that the engineering basis for grounding into a whole. Floor construction in each region, the region edges and other areas as lightning protection and grounding of the junction of beam main bars with a yellow paint marking[3], to ensure that the next area in the construction of the area with the reserved ground reinforcement accurately docking.

The Garage Construction Stage. Garage lightning protection construction stage according to the latest and has approval to deepen the drawings finished down lead welding construction and garage transformer room and each room ground reserved embedded, complete embedded artificial grounding lightning protection test point set aside first layer of exterior walls and a garage.

The Skirt Building Construction Stage. Podium construction stage, according to the latest lightning protection deepen the drawings and the examination and approval for podium area down lead connection, reserved or embedded computer room ground, top and skirt building lightning protection network welding.

The Tower Stage. Tower construction stage, according to the latest and the examination and approval of drawings for lightning protection downlead and each layer of equalizing ring welding construction, and equalizing ring with jumper down lead construction;

Complete room and bathroom on each floor equip grounding reserved, curtain wall windows and doors; Tower grounding and grounding of the roof construction (pre-construction and construction s cheme of local mine-ban negotiations). 


\section{The Main Construction Method}

Basic Grounding Network. Negative three-layer floor grounding grid in accordance with the design plan for the construction of lightning protection, grounding the use of ground floor grille floor two beam diameter greater than or equal to $16 \mathrm{~mm}$ steel welding formation. Grounding network in the pile foundation will be two main pile foundation reinforcement and ground net.through jumper with a diameter of $10 \mathrm{~mm}$ round steel. Used as ground net, through ground beam reinforced with $10 \mathrm{~mm}$ diameter in intersections and tapping the round steel welding, particular way as shown in Figure 2.

Wall Columns Using as Lightning Protection Downlead. The third phase of the project and podium area are using the column diagonal $16 \mathrm{~mm}$ diameter greater than or equal to two main reinforcement as lightning protection downlead, lightning protection downlead with reliable grounding network connection at the bottom, and at the main bar sleeve connection with diameter of 10MM round steel bridging. In the process of construction should not only strictly control the welding quality, but also to the value of the main reinforcement as downlead completes the logo with yellow paint, in order to avoid wrong welding short of lightning protection effect. Particular way is shown in Figure 3.

Tower Lightning Protection Downlead. Perimeter of the tower are steel columns and steel columns are equipped with a wire, the site columns are available as the lightning proof downlead[4], specific practices in steel column into place to bury two diagonally anchor bolts with grounding grid in the floor with a diameter greater than or equal to 10MM bar welded connection, steel columns in place anchor bolt and nut, steel column welding as a whole, form a vertical pathway has been on to the roof and roofing lightning protection system for reliable connections, as shown in Figure 4.

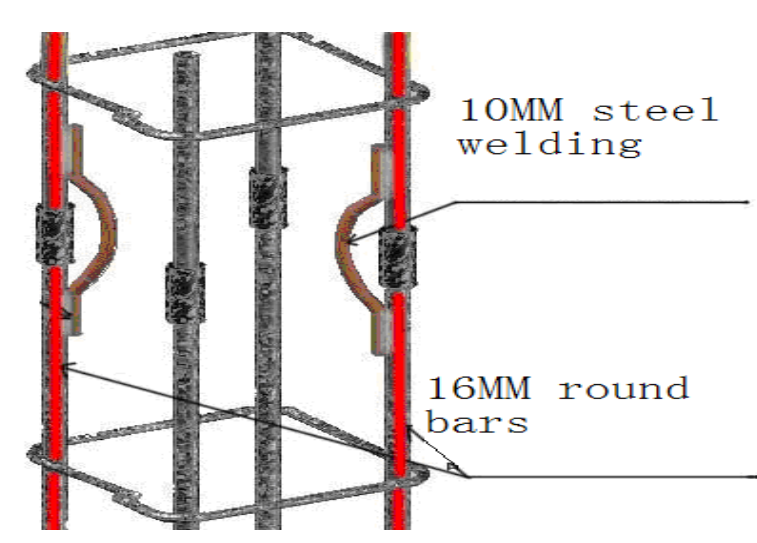

Fig. 3. Wire bridge diagram

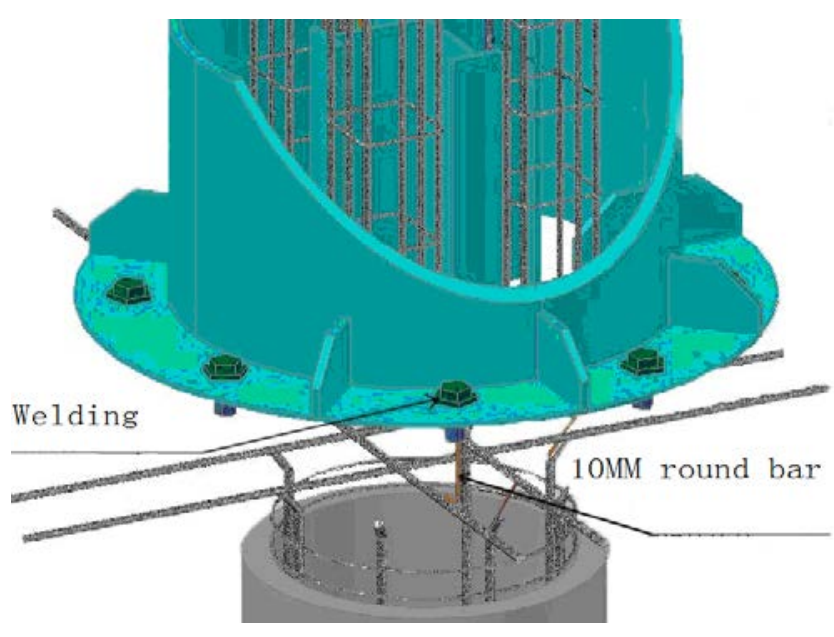

Fig. 4. Downlead schematic

Pressure Equalization Ring(PER). Flat-top floor of the tower and set for each floor above the pressure equalization ring(PER). The project will use perimeter beams and core of concrete beams in the two horizontal bars or unsightly steel welding connect and form a ring, frame formation is not more than $18 \mathrm{~m} * 18 \mathrm{~m}$ of beam and slab reinforcement mesh. Pressure equalization ring(PER) on each floor and down lead for reliable connections. As shown in Figure 5. 


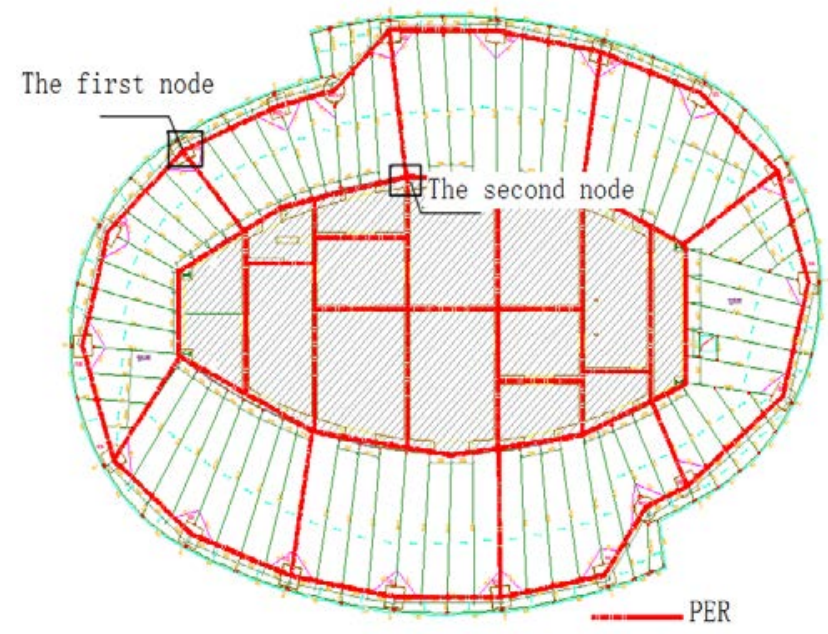

Fig. 5. Equalizing ring arrangement

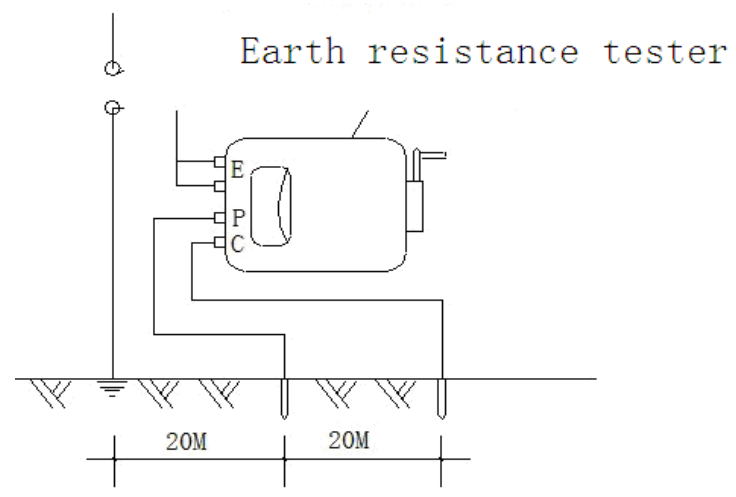

Fig. 6. Lightning protection test table wiring

Earthing Test. According to the design requirements, in the construction plan set ground test point for later testing regularly every year. Outdoor ground test point at the building perimeter distance $800 \mathrm{~mm}$, the test point location ended in lightning protection and grounding design development at the bottom of the approval prevail.

ZC-8 grounding resistance measurement of grounding resistance Tester, the measured resistance value shall meet the design and specifications. Measurement frequency at least 3 times for each local station, calculate the average of the data can be considered to be the point of grounding resistance value. Wiring as shown in Figure 6.

\section{Construction Technology}

Requirements for Lap Multiple of Steel. Steel grounding device should be welded connection, the overlap length should meet the following requirements:

Flat steel and flat lap is twice the width of flat steel, welded on three sides.

Round and round bar lap-bar diameter of 6 times, double-sided welding.

Lap for round and flat steel bar diameter of 6 times, double-sided welding.

Flat and round steel and steel pipe, steel plate welded to each other when, in addition to outside the contact spot welded on both sides, should be added to round steel lap joints.

Earthing connection should be reliable, connections should not be loose, unsoldering, poor contact. Natural grounding such as grading rings and metal pipe connections should be used in welding. Such as welding are in trouble, clamp connections can be used, but should have good electrical conductivity[5].

\section{Design of the Chip Kick Mechanics}

After the text edit has been completed, the paper is ready for the template. Duplicate the template file by using the Save As command, and use the naming convention prescribed by your conference for the name of your paper. In this newly created file, highlight all of the contents and import your prepared text file. You are now ready to style your paper.

Flat Welding. Select the appropriate welding electrode diameter welding current, welding, arc length, and so on, by welding procedure test.

Clean welding: welding, Assembly clearance check Groove whether it meets the requirements, solid welding, without oil, rust around the weld.

Baking temperature of welding electrodes shall be in conformity with the provisions and time, remove it from the oven electrode, electrode insulated bucket, ad-taking.

Welding current: according to the thickness of weld, welding, welding type, diameter, welder's proficiency and other factors, appropriate choice of welding current. 
Fillet weld arc: landing point in the arc weld end is larger than $10 \mathrm{~mm}$, should not hit the arc, the arc ignition after the electrode should be started immediately from the weld zone, keep $2 \sim 4 \mathrm{~mm}$ gap generated between the electrode and arc component.

Welding speed: the speed requirement welding to ensure uniform thickness, width of weld from the mask in molten pool of molten iron and slag equidistant (2 3mm).

Welding angle: according to two welding pieces of thickness determine. Dang welding pieces thickness ranging Shi, electrode and more thick welding pieces side angle should is greater than electrode and more thin welding pieces side angle.

Cleaning: the whole weld out clear molten slag welder test (including appearance and dimension, and so on) without problems, before relocation to continue welding.

Vertical Welding. Basic operating processes and welding the same, but should pay attention to the following issues: under the same conditions, than flat welding current welding power supply $10 \% \sim 15 \%$. Using short-arc welding, arc length is generally $2 \sim 3 \mathrm{~mm}$.

Arc welding: when to end, by will crater filled arc, arc moved to the central pool stopped arc. Is strictly prohibited to make the arc hang on one side. In order to prevent the bite of meat, the arc welding electrode angle should be lowered, so that the welding rod is vertically or slightly blown down by the arc.

Overhead Welding. Basic operating processes and welding the same, but should pay attention to the following issues: under the same conditions, than flat welding current welding power supply $10 \% \sim 15 \%$. Using short-arc welding, arc length is generally $2 \sim 3 \mathrm{~mm}$.

Arc welding: when to end, by will crater filled arc, arc moved to the central pool stopped arc. Is strictly prohibited to make the arc hang on one side. In order to prevent the bite of meat, the arc welding electrode angle should be lowered, so that the welding rod is vertically or slightly blown down by the arc.

Overhead Welding. The basic and vertical welding, horizontal welding the same, the electrode and welding parts of the angle and the welding thickness of the electrode and the welding direction into $70^{\circ} \sim 80^{\circ}$ angle, it is appropriate to use small current, short arc welding.

\section{Test}

At present the main means is low click type and the lever type, low click type is on the bottom of the ball through attack the ball flew over obstacles, this method is able to pick the ball's advantages and makes the energy loss in institutions.

After the welding is completed, needs to be tested, monitor and improve weld quality, acceptance by weld inspection method, final inspection using grounding resistor Tester.

After the welding is completed, needs to be tested, monitor and improve weld quality, acceptance by weld inspection method, final inspection using grounding resistor Tester.

Grounding resistance is less than $1 \Omega$.

According to the first self-check, after inspection procedures for inspection and acceptance.

\section{Quality Requirements}

Appearance of the quality inspection pass, each time the hidden works one-time acceptance by the owners and supervision engineers.

Lightning grounding system to form a reliable electrical path, the final one-time through the Quality Supervision Station, the Office of lightning protection and other government departments completed and acceptance.

\section{Acknowledgement}

This paper is aided by following Dongguan Institute of Technology "The key technology research of the mobile WiMAX system ", which project number: 2008108101006. 


\section{References}

[1] Martin; Robin. Testing emergency lighting systems [J] Consulting - Specifying Engineer 2009.04.

[2] Lein, Peter.Protection of mechanical and electrical building equipment from lightning and overloads[J].VDI Berichte. 2006.05.

[3] Chang, Jing-Yi Kuan, Yean-Der.Integrated application of renewable energy technology in building energy efficiency [J].Applied Mechanics and Materials.2012.12.

[4] Zhang Feizhou, Liu Shanghe. A New function to RePresent the lightning Return stroke Currents.IEEETransaetionsonEleetromagnetieComPatibility, 2002,44(4);595一598.

[5] Liu Shanghe.Development and Applieation of LEMP - simulating Deviee. Asia-Pacific Conference on Environmental Electromagnetic, 2000:147-151. 